\title{
Data envelopment analysis with missing data: An application to life insurance industry in Taiwan
}

\author{
Yueh-Chiang Lee $\mathrm{a}^{*}$, Yao-Hung Yang $\mathrm{b}^{*}$ \\ a Department of Business Administration, Vanung University, Taiwan \\ b Department of Business Administration, Chung Yuan Christian University, Taiwan \\ ${ }^{*}$ Corresponding author's e-mail: yaohungyang@yahoo.com.tw
}

\section{H I G H L I G H T S:}

1. The study uses the financial statement data of Taiwanese insurance industry from 2008 to 2012.

2. The Financial Holding Company's (FHC) cross-selling generate synergy which benefits life insurance.

3. FHC insurance's operational efficiency is better than non-FHC.

4. The use of fuzzy DEA solves the uncertainty of missing data.

\section{Article History}

Received: 12-11-2014

Accepted: 19-12-2014

Available online: 25-12-2014

Keywords:

Financial holding company;

Fuzzy data envelopment analysis model;

Life insurance;

Operational efficiency.

JEL Classification:

C1; G2; M2.

(C) 2014 The Authors. This is an open access article under the terms of the Creative Commons Attribution License 4.0, which allows use, distribution and reproduction in any medium, provided the original work is properly cited.

\subsection{Introduction}

Unable to cope with business losses over the years, MetLife Taiwan started to dismiss its conventional business sections at the end of 2006 and also began to consider selling the company. In October 2009, it made the decision to pull out of the Taiwan market. ChinaTrust Financial Holdings purchased all its shares with US\$180 million in March 2011. Share transfer was completed in November the same year and MetLife Taiwan became a member of ChinaTrust Financial Holdings. Meanwhile, Dutch-run ING Aetna Life Insurance also withdrew from the life insurance market in Taiwan and sold the business to Fubon Life Insurance, a local enterprise. In early 2009, Prudential Life Insurance Taiwan transferred all the liabilities and assets of insurance policies sold by salespeople to China Life Insurance (Taiwan) and shifted its focus on insurance through telephone marketing and banks. Dutchbased Aegon sold its TransGlobe Life Insurance Taiwan to Chung Wei Yi Co., Ltd., a financial holding company, in the same year. In 2011, Run Chen Investment Holdings signed a contract with US-based AIG and purchased $97.57 \%$ of the shares of Nan Shan Life Insurance with US $\$ 2.16$ billion. 
The abovementioned life insurance company mergers aroused the concern of the public about the operational efficiency of foreign life insurance companies and the reason why they pulled out from the Taiwan market one after another. Coincidentally, a significant change also occurred to the financial environment in Taiwan around the same time. The Financial Institutions Merger Act was passed in 2000, allowing banks, securities firms and insurance companies to make cross-industry mergers. In 2001, the Financial Holding Company (FHC) Act was passed and enforced in November the same year. It greatly reduced the restrictions on cross-industry operations between financial institutions, making it possible for banks, securities firms and insurance companies, subsidiaries of financial holding companies, to reduce operating costs and maximize the benefits of consolidated management through cross selling, exchange and use of information, and equipment sharing. This change in the management environment made it even more difficult for insurance companies that were not affiliated with financial holding companies. For this reason, insurance companies had to reexamine and evaluate their operational efficiency to understand their own advantages and disadvantages and distribute their resources effectively.

Data envelopment analysis (DEA) has been extensively applied in a large number of studies on operational efficiency in the financial industry (Yang, 2006; Luhnen, 2009; Lu, Wang \& Lee, 2011; Hu, Yu \& Lin, 2012). To overcome the lack of management information in one-stage DEA, Seiford and Zhu (1999) first applied two-stage DEA to analyze the profitability and market power of the top 55 banks in the US. The numbers of input and output items were fixed. However, when there were missing input or output data, assessment became impossible. There are 30 life insurance companies in Taiwan and most of them have not yet gone public; hence, collection of complete input and output data is not easy. However, this has led to the idea of using the fuzzy DEA applied by Kao and Liu $(2000,2004)$ to explore the management performance of life insurance companies in Taiwan. Is it true that life insurance companies affiliated with financial holding companies are able to upgrade their operational efficiency through cross selling between the banks, life insurance companies and securities firms under the same financial holding company or the diversity of business operations or the massiveness of organization can lead to decrease in operational efficiency? Is there difference in operational efficiency between life insurance companies affiliated with financial holding companies and those not affiliated with financial holding companies? The empirical results of this study should be able to shed light on how life insurance businesses in the country can make effective adjustments to their resource distribution and management strategies in order to improve their operational efficiency and competitiveness. In the meantime, it is also hoped that these results can serve as referential management performance indexes for the general public, investment organizations, and supervising agencies.

\section{$2.0 \quad$ Literature review}

After decades of development, the life insurance industry in Taiwan has achieved maturity. Progress has been accomplished in various areas, such as the supervision system, product development, and consumer awareness, etc. After the Financial Holding Company Act was passed in 2001 and Taiwan became a member of the WTO in 2002, Taiwan officially entered the bancassurance era. The management of life insurance businesses transformed from relying on salespeople to integrating banks, insurance brokers/agents, and direct marketing, carried out in diverse approaches. Facing fierce competition in the life insurance market, each life insurance company had to adopt the most advantageous management style or strategy, reinforce its management constitution, and expand its operation scale effectively to boost operational efficiency. In addition, the synergic effects generated after financial holding companies were formed made it all the more difficult for insurance companies not affiliated with financial holding companies to compete in the market. To break the deadlock, these life insurance companies started to develop niche products gradually and market them through different channels to fight life insurance companies affiliated with financial holding companies. Therefore, it is necessary for each company to measure its operational efficiency to understand its advantages and disadvantages and make effective distribution of the various resources of the company.

Berger, Hunter Timme (1993) suggested use of DEA to deal with the problem of excessive output or input encountered by decision making units (DMUs), maintain units invariance, and keep the weight unaffected by subjective factors. It was a remarkable overall index for measuring the efficiency of financial institutions. Fukuyama (1997) applied DEA to assess the difference in management performance between mutual insurance companies and regular life insurance companies in Japan and also studied the productivity changes happening between 1988 and 1993. The empirical results showed that there was no significant difference in management performance between the two types of companies. The technical inefficiency of mutual insurance companies was mainly pure technical inefficiency, whereas the technical inefficiency of regular insurance companies was a result of scale inefficiency. Meanwhile, Donni and Fecher (1997) used the Malmquist index (MI) and DEA to study the insurance industry of 15 OECD member states between 1983 and 1991. The results indicated that the growth of productivity in each country was mainly attributed to technological advancements. They further observed certain characteristics of the insurance market in each country and discovered that reinsurance rate and market share seemed able to facilitate efficiency upgrades in these OECD member states. Cummins, Tennyson and Weiss (1999) employed DEA to examine the US life insurance industry from 1988 to 1995 and concluded that companies having engaged in acquisitions outperformed those not having engaged in acquisitions, financially feeble companies were the mostly 
likely to become acquisition targets, and mergers had a positive effect on the efficiency of life insurance businesses. Diacon (2001) used a DEA BCC model to measure the operational efficiency of British insurance businesses as well as evaluate 431 insurance companies in 6 European countries. The study revealed that the level of efficiency was related to the U-shaped scale of insurance companies. In other words, insurance companies of smaller or larger scales had better operational efficiency. The higher the percentage of the total premiums over the years, the better the operational efficiency would be. In comparison, French and German insurance companies had better technical efficiency than insurance companies in the UK and other countries.

Barros, Nektarios and Assaf (2010) discovered in their study that consolidation to expand operation scales was the driving force for improvement of operational efficiency adopted by Greek life insurance businesses. Moreover, the empirical results also confirmed that, compared to other life insurance companies, life insurance companies of larger scales, listed life insurance companies, and life insurance companies that had gone through consolidation had higher operational efficiency.

Lu, et al. (2011) performed a study on 25 life insurance companies in Taiwan between 2003 and 2006 and applied metafrontier data envelopment analysis to estimate technical efficiency and the metatechnology ratio (MTR). The empirical results showed that old local insurance companies were the most efficient. Besides having the best technical efficiency, they also adopted production technologies closest to metatechnology standards. In addition, the metatechnology ratio values of old local insurance companies and foreign insurance companies were significantly higher than those of new local insurance companies. Hu, et al. (2012) applied two-stage DEA to analyze the efficiency 29 life insurance companies in Taiwan between 2005 and 2009 and adjusted the negative values of input and output items according to the approach employed by Lovell and Pastor (1995). The empirical results revealed that, except for 2009, the overall efficiency of the insurance companies appeared to be rising slightly. They also indicated that insurance companies affiliated with financial holding companies and foreign life insurance companies had higher efficiency values. According to the above literature, a hypothesis is induced as follows.

$\mathrm{H}$ : Life insurance companies are affiliated with financial holding companies have better operating efficiency than life insurance companies are not affiliated with financial holding companies in Taiwan.

\subsection{Research design}

In DEA literature, it is generally assumed that the input and output items are fixed numbers. However, it is not impossible that some input or output data are inaccurate or missing. Kao and Liu (2000, 2004), Inuiguchi and Tanino (2000), and Hsieh and Hsu (2009) therefore adopted fuzzy linear mathematics to cope with such uncertain factors during production process. Besides assessing data with fuzzy features, fuzzy DEA can also be used to construct the upper and lower limits of efficiency value while also obtain valuable information between the intervals contained in these limits. The samples in this study are life insurance companies in Taiwan. As many of them have not yet gone public, collection of data has not been easy and the problem of missing data exists. Therefore, in this paper, fuzzy DEA is employed to analyze the operational efficiency of life insurance companies. This chapter will first describe the sample data sources and variable definitions and then explain the fuzzy DEA and fuzzy sorting.

\subsection{Data sources and variable definitions}

Some of the sample life insurance companies have not yet gone public; therefore, besides the data from Taiwan Economic Journal, related financial statements provided by the Life Insurance Association of ROC have also been referred to. After taking out companies less than 5 years old and the ones on which there is not enough information, the samples are as follows: 6 life insurance companies that are affiliated to financial holding companies, namely Fubon Life Insurance (FB), Cathay Life Insurance (CA), Shin Kong Life Insurance (SK), First-Aviva Life Insurance (FI), Bank Taiwan Life Insurance (TB), and BNP Paribas TCB Life (CO); and 17 life insurance companies that are not affiliated to financial holding companies, namely China Life (CL), Nan Shan Life (NL), Kuo Hua Life (KL), PCA Life (PCL), Global Life (GL), Hontai Life (HL), Chaoyang Life (CYL), Singfor Life (SL), Farglory Life (FL), Taiwan Life (TL), TransGlobe Life (TGL), Allianz Life (AL), Mercuries Life Insurance (MLI), New York Life (NYL), Prudential Life (PL), CIGNA Life (CL), and Manu Life (ML).

Life insurance companies are deemed in this paper as intermediate organizations to provide financial services. In other words, they are intermediates that transfer financial resources, not producers. Therefore, the intermediate approach is adopted to define the input and output items (Isik \& Hassan, 2002; Bonin, Hasan \& Wachtel, 2005). In selection of input variables, due to the fact that the business of a life insurance company mainly relies on the field staff to sell policies and the size of field staff is therefore always a few times larger than the size of office staff, this means that field staff is very important to the management performance of a life insurance company. Therefore, the total of the field staff and the office staff is regarded the number of employees of a life insurance company. Other 
than the number of employees, the input variables also include the fixed assets and operating expenses (Cummins et al., 1999; Lu et al., 2011). As for output variables, besides the premiums collected that are a source of revenue for a life insurance company, the company also has to use its assets to make proper investments. Therefore, investment income is another source of revenue for a life insurance company (Cummins et al., 1999; Lu, et al., 2011; Hu, et al., 2012) See Table 1 for the setting of input and output variables.

\begin{tabular}{lll}
\hline & \multicolumn{1}{c}{ Table 01: Definitions of input and output items } & \\
\hline Variable & Description & Unit \\
\hline Employees & $\begin{array}{l}\text { Total number of employees on the payroll in the fiscal year } \\
\text { Tangible assets having been used at least one year for } \\
\text { business purposes, not for sale }\end{array}$ & Thousand NT \\
Fixed Assets & $\begin{array}{l}\text { The expenses for marketing, management, R\&D, etc. during } \\
\text { the period in concern }\end{array}$ & Thousand NT \\
Operating expenses & $\begin{array}{l}\text { The premiums collected for sold policies } \\
\text { The income from the insurance company's long- and short- } \\
\text { Insurance Premium } \\
\text { Investment Income }\end{array}$ & Thousand NT \\
\hline
\end{tabular}

Since the relative efficiency calculated with DEA is based on the input and output items of each decision-making unit, a certain relationship between the numbers of input and output items and the number of decision-making units has to be maintained; the number of units to be evaluated must be at least two times that of the input items and the output items (Bowlin, 1987; Golany \& Roll, 1989). In this study, there are 3 input items, 2 output items, and 23 units to be evaluated. The arrangement complies with the rule.

\subsection{Fuzzy data envelopment analysis}

In this study, the fuzzy DEA developed by Kao and Liu (2000) to analyze fuzzy interval data is adopted. The input and output variables are defined as a triangular fuzzy number. Using a BCC input-oriented model for the hypothesis and applying $\alpha$-Cut and the extension principle, the fuzzy DEA model is simplified into a conventional DEA model containing parameters of $\alpha$ level. At specific $\alpha$ levels, the model can be used to obtain the upper and lower limits of efficiency.

Input variables are defined as $\left[\left(X_{i j}\right)_{\alpha}^{L},\left(X_{i j}\right)_{\alpha}^{U}\right]$, output variables $\left\lfloor\left(Y_{i k}\right)_{\alpha}^{L},\left(Y_{i k}\right)_{\alpha}^{U}\right\rfloor$, and efficiency values $\left[\left(\theta_{r}\right)_{\alpha}^{L},\left(\theta_{r}\right)_{\alpha}^{U}\right]$ respectively being the upper and lower limit intervals of $\alpha-C u t$ of $\tilde{X}_{i j}, \tilde{Y}_{i j}$ and $\tilde{\theta}_{i j}$; $\left[\left(\theta_{r}\right)_{\alpha}^{L}\right]$ and $\left\lfloor\left(\theta_{r}\right)_{\alpha}^{U}\right\rfloor$ can be calculated with the following formula:

$$
\begin{aligned}
& \left(\theta_{r}\right)_{\alpha}^{L}=\max \left(\sum_{k=1}^{t} u_{k}\left(Y_{r k}\right)_{\alpha}^{L}-u_{0}\right) / \sum_{j=1}^{s} v_{j}\left(X_{r j}\right)_{\alpha}^{U} \\
& \text { s.t. }\left(\sum_{k=1}^{t} u_{k}\left(Y_{r k}\right)_{\alpha}^{L}-u_{0}\right) / \sum_{j=1}^{s} v_{j}\left(X_{r j}\right)_{\alpha}^{U} \leq 1 \\
& \left(\sum_{k=1}^{t} u_{k}\left(Y_{i k}\right)_{\alpha}^{U}-u_{0}\right) / \sum_{j=1}^{s} v_{j}\left(X_{i j}\right)_{\alpha}^{L} \leq 1, i=1,2, \ldots, n, i \neq r \\
& k=1,2, \ldots, t, j=1,2, \ldots, s
\end{aligned}
$$

$u_{k}, v_{j} \geq \varepsilon>0, u_{0}$ There is no positive or negative limit.

$\left(\theta_{r}\right)_{\alpha}^{U}=\max \left(\sum_{k=1}^{t} u_{k}\left(Y_{r k}\right)_{\alpha}^{U}-u_{0}\right) / \sum_{j=1}^{s} v_{j}\left(X_{r j}\right)_{\alpha}^{L}$

s.t. $\left(\sum_{k=1}^{t} u_{k}\left(Y_{r k}\right)_{\alpha}^{U}-u_{0}\right) / \sum_{j=1}^{s} v_{j}\left(X_{r j}\right)_{\alpha}^{L} \leq 1$ 
$\left(\sum_{k=1}^{t} u_{k}\left(Y_{i k}\right)_{\alpha}^{L}-u_{0}\right) / \sum_{j=1}^{s} v_{j}\left(X_{r j}\right)_{\alpha}^{U} \leq 1, i=1,2, \ldots, n, i \neq r$

$k=1,2, \ldots, t, j=1,2, \ldots, s$

$u_{k}, v_{j} \geq \varepsilon>0, u_{0}$ There is no positive or negative limit.

$\left(\theta_{r}\right)_{\alpha}^{L}=$ the lower limit of efficiency value of target decision-making unit $\mathrm{r}$ at $\alpha$ level;

$\left(\theta_{r}\right)_{\alpha}^{U}=$ the upper limit of efficiency value of target decision-making unit $\mathrm{r}$ at $\alpha$ level;

$\left(X_{r j}\right)_{\alpha}^{L}=$ the lower limit of the quantity of no. $\mathrm{j}$ input item of target decision-making unit $\mathrm{r}$ at $\alpha$ level;

$\left(X_{r j}\right)_{\alpha}^{U}=$ the upper limit of the quantity of no. j input item of target decision-making unit $\mathrm{r}$ at $\alpha$ level

$\left(Y_{r k}\right)_{\alpha}^{L}=$ the lower limit of the quantity of no. k output item of target decision-making unit $\mathrm{r}$ at $\alpha$ level;

$\left(Y_{r k}\right)_{\alpha}^{U}=$ the upper limit of the quantity of no. k output item of target decision-making unit $\mathrm{r}$ at $\alpha$ level;

$\left(X_{i j}\right)_{\alpha}^{L}=$ the lower limit of the quantity of no. j input item of no. i decision-making unit at $\alpha$ level;

$\left(X_{i j}\right)_{\alpha}^{U}=$ the upper limit of the quantity of no. j input item of no. i decision-making item at $\alpha$ level;

$\left(Y_{i k}\right)_{\alpha}^{L}=$ the lower limit of the quantity of no. k output item of no. i decision-making unit at $\alpha$ level;

$\left(Y_{i k}\right)_{\alpha}^{U}=$ the upper limit of the quantity of no. k output item of no. i decision-making unit below $\alpha$ level;

$u_{\mathrm{k}}=$ the weight of no. $\mathrm{k}$ output item; $\mathrm{v}_{\mathrm{j}}=$ the weight of no. $\mathrm{j}$ input item

$\varepsilon=10^{-4}$ or $10^{-6}$ as normally set

$u_{0}$ the intercept term

\subsection{Fuzzy number comparison index}

Unlike the crisp values obtained with conventional DEA models, the efficiency values obtained with the fuzzy DEA model are fuzzy numbers; therefore, it is difficult to conduct sorting on the units evaluated. In this study, the area estimation approach proposed by Chen and Klein (1997) is adopted to sort the fuzzy numbers. At $\alpha$ level, there is the decision-making unit $\mathrm{i}(\mathrm{i}=1,2, \ldots, \mathrm{n})$ and the upper and lower limits of efficiency value $\theta_{r}$ are respectively $\left(\theta_{r}\right)_{\alpha}^{L}$ and $\left(\theta_{r}\right)_{\alpha}^{U}$. By definition, $\mathrm{h}(\mathrm{X})=1$ stands for the maximum height $(\alpha=1)$ and $\alpha_{\mathrm{b}}=\mathrm{b} / \mathrm{w}, \mathrm{b}=0.1,0.2, \ldots ., \mathrm{w}$; in other words, $\alpha_{0}=0.0, \alpha_{1}=0.1, \ldots \ldots ., \alpha_{10}=1$; therefore the comparison index (CI) is:

$C I_{i}=\frac{\sum_{b=0}^{w}\left(\left(\theta_{i}\right)_{\alpha_{b}}^{U}-c\right)}{\left[\sum_{b=0}^{w}\left(\left(\theta_{i}\right)_{\alpha_{b}}^{U}-c\right)-\sum_{b=0}^{w}\left(\left(\theta_{i}\right)_{\alpha_{b}}^{L}-d\right)\right]}$

$\left(\theta_{i}\right)_{\alpha_{b}}^{L}=$ the lower limit of efficiency value of decision-making unit I;

$\left(\theta_{i}\right)_{\alpha_{b}}^{U}=$ the upper limit of efficiency value of decision-making unit I;

$c=\min \left\{\left(\theta_{i}\right)_{\alpha_{b}}^{L}\right\} d=\max \left\{\left(\theta_{i}\right)_{\alpha_{b}}^{U}\right\}$. The sorting principle is that the larger the $C I_{i}$ value, the higher the ranking.

\subsection{Empirical results}

This study was conducted on life insurance companies, 23 in total, in Taiwan between 2008 and 2012. Take the data for 2012 data as an example. The investment income figure for CIGNA Life is missing, as shown in Table 2.

\begin{tabular}{llllll}
\hline \multicolumn{5}{c}{ Table 02: Life insurance company input and output variables } \\
DMUs & $\begin{array}{l}\text { Employees } \\
\text { (person) }\end{array}$ & $\begin{array}{l}\text { Fixed Asset } \\
\text { (Thousand NT) }\end{array}$ & $\begin{array}{l}\text { Operating } \\
\text { expenses } \\
\text { (Thousand NT) }\end{array}$ & $\begin{array}{l}\text { Insurance } \\
\text { premiums } \\
\text { (Thousand NT) }\end{array}$ & $\begin{array}{l}\text { Investment } \\
\text { income }\end{array}$ \\
TB & 5,648 & 893,222 & 840,423 & $56,697,442$ & $10,208,200$ \\
\end{tabular}




\begin{tabular}{llllll} 
TL & 4,498 & $9,836,433$ & $2,624,008$ & $67,610,451$ & $15,343,225$ \\
PCL & 718 & 73,043 & $2,174,019$ & $21,339,630$ & $6,139,689$ \\
CA & 30,889 & $20,508,928$ & $16,134,194$ & $471,820,605$ & $119,271,028$ \\
CL & 5,181 & $4,854,110$ & $3,341,642$ & $115,577,332$ & $26,472,589$ \\
NL & 18,092 & $12,177,214$ & $14,500,158$ & $352,729,473$ & $82,904,992$ \\
KL & 2,700 & 400,551 & $1,492,220$ & $36,771,296$ & $10,896,254$ \\
SK & 11,356 & $14,192,745$ & $12,851,151$ & $162,367,489$ & $68,007,294$ \\
FB & 17,739 & $7,395,030$ & $13,157,079$ & $401,449,260$ & $68,097,646$ \\
GL & 614 & 113,524 & 479,299 & $8,516,802$ & $1,180,712$ \\
MLI & 6,773 & $4,226,604$ & $3,876,625$ & $103,890,522$ & $15,315,113$ \\
CYL & 249 & 155,506 & 304,794 & $8,495,689$ & 490,649 \\
SL & 686 & 17,053 & 760,784 & $8,693,829$ & $1,790,980$ \\
FL & 1,763 & $8,726,315$ & $1,620,986$ & $36,498,273$ & $13,424,564$ \\
HL & 485 & 302,639 & 625,861 & $22,618,716$ & $5,187,520$ \\
AL & 1,316 & 113,180 & $1,215,181$ & $4,679,402$ & 659,860 \\
FI & 188 & 4,851 & 364,400 & $2,474,901$ & 368,779 \\
PL & 1,152 & $1,365,586$ & $1,712,333$ & $11,474,736$ & $1,661,718$ \\
TGL & 926 & 178,686 & $1,796,514$ & $25,191,738$ & $8,825,842$ \\
NYL & 640 & 33,067 & $1,047,296$ & $11,006,193$ & $1,787,727$ \\
CL & 938 & 168,366 & $2,314,288$ & $7,346,983$ & $*$ \\
ML & 1,376 & 50,964 & 921,294 & $6,892,806$ & 736,459 \\
CO & 255 & 20,748 & 925,367 & $3,037,692$ & 171,220 \\
* missing data & & & & \\
\hline & & & & & \\
\hline
\end{tabular}

In this paper, according to the input and output items, the minimum, maximum and median are selected to be the most pessimistic value, most optimistic value and most likely value to construct a triangular membership function and form the lower limit, upper limit and vertex. Then the data in Table 2 are converted into $\alpha-$ Cut and presented as interval data. The 2012 data, for instance, are as shown in Table A.1.

Next, the calculation approach defined by Kao and Liu (2000) is applied. $\alpha$ is divided into 10 intervals; in other words, $\alpha=0.0,0.1,0.2, \ldots, 1.0$, forming $11 \alpha$ values. The different upper and lower limit interval values of $\alpha-$ Cut are calculated. Using the 2012 data as an example, the upper and lower limits of efficiency value calculated with the DEA-Solver software are as shown in Table A.2.

After obtaining the upper and lower limits of efficiency value of life insurance companies in Taiwan between 2008 and 2012, the area estimation approach proposed by Chen and Klein (1997) is applied to calculate and establish the fuzzy number comparison index for each year. Then, the indexes are added up and the performance rankings of the life insurance companies are determined in accordance with the total index; the larger the index, the higher the ranking, as shown in Table 3.

\begin{tabular}{llclllll}
\hline & \multicolumn{7}{c}{ Table 03: Life insurance company performance rankings 2008-2012 } \\
DMU & 2008 & 2009 & 2010 & 2011 & 2012 & Sum & Rank \\
TB & 1.000 & 1.000 & 1.000 & 1.000 & 1.000 & 5.000 & 1 \\
CA & 1.000 & 1.000 & 1.000 & 1.000 & 1.000 & 5.000 & 1 \\
FB & 1.000 & 1.000 & 1.000 & 1.000 & 1.000 & 5.000 & 1 \\
CYL & 1.000 & 1.000 & 1.000 & 1.000 & 1.000 & 5.000 & 1 \\
FI & 1.000 & 1.000 & 1.000 & 1.000 & 1.000 & 5.000 & 1 \\
SL & 0.774 & 1.000 & 1.000 & 1.000 & 1.000 & 4.774 & 6 \\
HL & 0.744 & 1.000 & 1.000 & 1.000 & 1.000 & 4.744 & 6 \\
CL & 1.000 & 0.699 & 1.000 & 1.000 & 1.000 & 4.699 & 8 \\
FL & 1.000 & 1.000 & 1.000 & 0.896 & 0.781 & 4.677 & 9 \\
CO & 0.937 & 1.000 & 1.000 & 1.000 & 0.682 & 4.620 & 10 \\
NYL & 0.632 & 1.000 & 1.000 & 1.000 & 0.978 & 4.610 & 11 \\
PCL & 0.490 & 1.000 & 1.000 & 1.000 & 1.000 & 4.490 & 12 \\
GL & 0.690 & 0.984 & 0.998 & 0.862 & 0.849 & 4.383 & 13 \\
KL & 0.833 & 0.736 & 0.822 & 0.974 & 1.000 & 4.364 & 14 \\
TGL & 0.841 & 0.793 & 1.000 & 0.674 & 1.000 & 4.308 & 15 \\
NL & 0.907 & 0.901 & 0.675 & 0.799 & 0.985 & 4.267 & 16 \\
SK & 0.798 & 0.797 & 1.000 & 0.822 & 0.783 & 4.199 & 17 \\
ML & 1.000 & 0.884 & 0.525 & 0.674 & 0.490 & 3.573 & 18 \\
MLI & 0.798 & 0.883 & 0.525 & 0.478 & 0.677 & 3.361 & 19 \\
CL & 1.000 & 1.000 & 0.057 & 0.017 & 0.610 & 2.683 & 20 \\
TL & 0.455 & 0.755 & 0.457 & 0.330 & 0.607 & 2.603 & 21 \\
PL & 0.723 & 0.878 & 0.044 & 0.041 & 0.004 & 1.690 & 22 \\
AL & 0.067 & 0.020 & 0.117 & 0.105 & 0.088 & 0.396 & 23
\end{tabular}


Table 3 indicates that the operational efficiency of TB, CA, FB, CYL and FI was the best in the five years from 2008 to 2012. Their efficiency value achieved 1 each year, apparently better than the remaining life insurance companies. According to the classification of Norman and Stocker (1991), these five companies are robustly efficient units and are able to remain efficient unless critical changes occur in the future. Their scales of return should be constant; hence, there is no need to increase output or decrease input. They only need to maintain the current production scale. Among these five companies, TB, CA, FB and FI are subsidiaries of financial holding companies. Obviously, the synergy generated after a financial holding company is formed and the cross selling between the subsidiary groups can give an affiliated life insurance company a lot of help.

Besides in 2008, the operational efficiency value of SL and HL achieved 1 each year between 2009 and 2012, indicating increasingly improved operational efficiency. They also need not increase output or reduce input unless critical changes happen to the market in the future. The efficiency value of CL, except in 2009, was 1 in every one of the other years, signifying that the company is efficient and able to adjust its output and input to maintain its operational efficiency in the best condition. The efficiency value of FL, on the other hand, may have achieved 1 from 2008 to 2010, but it has become not so satisfactory in more recent years and needs to adjust its input items appropriately to improve the efficiency value. CO and NYL, however, appeared inefficient in 2008 and 2012 but exhibited decent operational efficiency from 2009 to 2011. It is suggested that they review the input items in 2008 and 2009 and make necessary adjustments. The efficiency value of PCL for 2008 was particularly low but the company immediately adjusted the input items and the operational efficiency value achieved 1 in each of the following years.

The efficiency value of the remaining life insurance companies rarely achieved 1 during the time of study, indicating poor operational efficiency as well as the inability of the managers to adjust the input items in time. The efficiency value of MLI, TL, PL and AL during the time of study was below 0.9 each year, making them distinctly inefficient units. It will be difficult for them to become efficient in a short time. They need to improve the input-output ratio and adjust their production scale simultaneously to become efficient.

\subsection{Conclusion and policy implication}

Liu et al. (2011) applied metafrontier data envelopment analysis to study life insurance companies in Taiwan. The empirical results showed that the metatechnology ratio of old local insurance companies and foreign insurance companies was significantly higher than that of new insurance companies. Hu et. al. (2012) adjusted the negative values of input or output items and the empirical DEA results indicated that the efficiency value of insurance companies affiliated with financial holding companies and foreign life insurance companies was better. In this paper, it is also proven that the operational efficiency of insurance companies TB, CA, FB and FI, all affiliated to financial holding companies, was indeed superior to that of insurance companies not affiliated to financial holding companies. This is consistent with the empirical results of Hu et al. (2012). Obviously, these four life insurance companies are able to boost their operational efficiency as a result of cross selling through the banks, life insurance companies and securities firms under the same financial holding company. However, the operational efficiency of CO and SK, also affiliated to financial holding companies, is not so decent, probably a result from the diversity of business operations or immensity of organization. Meanwhile, the five life insurance companies proven to be with the best efficiency in this paper are all local companies. This is not consistent with the empirical results of Lu et al. (2011) and Hu et al. (2012). Besides that different DEA models have been used, the difference in time of study and the dissimilarity in input and output items could have led to inconsistent results.

This paper shows that insurance companies that are not affiliated to financial holding companies generally are not efficient. Among them, CYL is the only one with efficiency value achieving 1 every year for five consecutive years. The other insurance companies all need to adjust their input items appropriately to boost efficiency. As life insurance businesses have transformed from relying on salespeople to diversified marketing through banks and securities firms, competition in the life insurance market has intensified and the room for insurance companies not affiliated to financial holding companies has been suppressed, making their further growth increasingly difficult. In the future, they have to adopt the most advantageous management styles and management strategies to differentiate from insurance companies that are affiliated to financial holding companies.

In the past, the DEA models applied were often unable to compute due to missing input and output data. In this paper, fuzzy linear mathematics is employed to solve this uncertainty (Kao \& Liu , 2000; Hsieh \& Hsu, 2009). In the future, when data collection is difficult or there are missing data, researchers are suggested to adopt fuzzy DEA to analyze operational efficiency.

\section{Reference}


Barros CP., Nektarios M. Assaf A., 2010. Efficiency in the Greek insurance industry. European Journal of Operational Research, 205(2): 431-436. http://dx.doi.org/10.1016/j.ejor.2010.01.011

Berger AN., Hunter W C., Timme S G., 1993. The efficiency of financial institutions: A review and preview of research past, present and future. Journal of Banking \& Finance, 17(2-3): 221-249. http://dx.doi.org/10.1016/03784266(93)90030-H

Bonin JP., Hasan, I., Wachtel P., 2005. Bank performance, efficiency and ownership in transition countries. Journal of Banking and Finance, 29: 31-51. http://dx.doi.org/10.1016/j.jbankfin.2004.06.015

Bowlin W., 1987. Evaluating the efficiency of US Air Force real-property maintenance activities. Journal of the perational Research Society, 38(2): 127-135. http://dx.doi.org/10.2307/2582148

Chen CB., Klein, CM., 1997. A simple approach to ranking a group of aggregated fuzzy utilities. IEEE Transactions on Systems, Man Cybernet. Part B: Cybernet, 27(1): 26-35. http://dx.doi.org/10.1109/3477.552183

Cummins JD., Tennyson S., Weiss MA., 1999. Consolidation and efficiency in the US life insurance industry. Journal of Banking and Finance, 23(2-4): 325-357. http://dx.doi.org/10.1016/S0378-4266(98)00089-2

Diacon SR., 2001. The efficiency of UK general insurance companies. Working Paper, Centre for Risk \& Insurance Studies, University of Nottingham.

Donni O., Fecher F., 1997. Efficiency and productivity of the insurance industry in the OECD countries. The Geneva Papers on Risk and Insurance-Issues and Practice, 22(84): 523-535.

Fukuyama H., 1997. Investigating productive efficiency and productivity changes of Japanese life insurance companies. Pacific-Basin Finance Journal, 5 (4): 481-509. http://dx.doi.org/10.1016/S0927-538X(97)00016-4

Golany B., Roll Y., 1989. An application procedure for DEA. OMEGA, 17(3): 237-250. http://dx.doi.org/10.1016/0305-0483(89)90029-7

Hsieh LF., Hsu SM., 2009. A new fuzzy DEA ranking model with an application for bank branch performance evaluation. Journal of Management \& Systems, 16(3): 469-486.

Hu JL., Yu S., Lin FL., 2012. Efficiency analysis of life insurance companies in Taiwan: A two-stage data envelopment analysis. Insurance Issues and Practices, 11(1): 21-42.

Inuiguchi M., Tanino T., 2000. Data envelopment analysis with fuzzy input-output data. In Y. Y. Haimes and R. E. Steuer (Eds.), Research and Practice in Multiple Criteria Decision Making, Springer-Verlag, Berlin, 296-307. http://dx.doi.org/10.1007/978-3-642-57311-8_25

Isik I., Hassan MK., 2002. Technical, scale and allocative efficiencies of Turkish banking industry. Journal of Banking and Finance, 26(4): 719-766. http://dx.doi.org/10.1016/S0378-4266(01)00167-4

Kao C., Liu S T., 2000. Data envelopment analysis with missing data: An application to university libraries in Taiwan. Journal of the Operational Research Society, 51: 897-905. http://dx.doi.org/10.2307/254045

Kao C., Liu ST., 2004. Predicting bank performance with financial forecasts: A case of Taiwan commercial banks. Journal of Banking and Finance, 28(10): 2353-2368. http://dx.doi.org/10.1016/j.jbankfin.2003.09.008

Lovell CAK., Pastor JT., 1995. Units invariant and translation invariant DEA models. Operations Research Letters, 18(3): 147-151. http://dx.doi.org/10.1016/0167-6377(95)00044-5

Lu YH., Wang CH., Lee CH., 2011. The differences in technology efficiency of Taiwan's life insurance companies - The application of the Metafrontier DEA model. Journal of Economics and Management, 7(1): 73-100.

Luhnen M., 2009. Determinants of efficiency and productivity in German property-liability insurance: evidence for 1995-2006. The Geneva Papers on Risk and Insurance, 34(3): 483-505. http://dx.doi.org/10.1057/gpp.2009.10

Norman M., Stocker B., 1991. Data envelopment analysis: The assessment of performance? John Wiley and Sons.

Seiford LM., Zhu J., 1999. Profitability and marketability of the top 55 U.S. commercial banks. Management Science, 45(9): 1270-1288. http://dx.doi.org/10.1287/mnsc.45.9.1270

Yang Z., 2006. A two-stage DEA model to evaluate the overall performance of Canadian life and health insurance companies. Mathematical and Computer Modeling, 43(7-8): 910-919.

http://dx.doi.org/10.1016/j.mcm.2005.12.011 
Appendix tables:

Table a.1: Life insurance company input and output intervals in 2012

\begin{tabular}{|c|c|c|c|c|c|}
\hline DMUs & Employees & Fixed Asset & Operating expenses & Insurance premium & Investment Income \\
\hline TB & $\lceil 5648,5648\rceil$ & $\lceil 893222,893222 〕$ & {$[840423,840423]$} & $\lceil 56697442,56697442 〕$ & $\lceil 10208200,10208200\rfloor$ \\
\hline TL & {$[4498,4498]$} & 〔9836433, 9836433$]$ & {$[2624008,2624008]$} & $\{67610451,67610451 〕$ & 〔 $15343225,15343225 〕$ \\
\hline PCL & $\lceil 718,718 〕$ & {$[73043,73043]$} & 〔2174019, 2174019〕 & 〔 $21339630,21339630 〕$ & 〔6139689, 6139689〕 \\
\hline $\mathrm{CA}$ & {$[30889,30889]$} & 〔 20508928,20508928 〕 & $〔 16134194,16134194 〕$ & 〔 $471820605,471820605 〕$ & 〔 119271028,119271028 〕 \\
\hline CL & $\lceil 5181,5181]$ & $\lceil 4854110,4854110 〕$ & 〔 $3341642,3341642 〕$ & 〔 $115577332,115577332 〕$ & 〔26472589, $26472589 〕$ \\
\hline NL & 〔 18092,18092$]$ & $\lceil 12177214,12177214 〕$ & 〔 $14500158,14500158 〕$ & 〔 $352729473,352729473 〕$ & 〔 $82904992,82904992 〕$ \\
\hline KL & $\lceil 2700,2700 〕$ & $\lceil 400551,400551 〕$ & {$[1492220,1492220]$} & 〔36771296, $36771296 〕$ & 〔 10896254,10896254$]$ \\
\hline SK & {$[11356,11356]$} & 〔 $14192745,14192745 〕$ & $〔 12851151,12851151 〕$ & [ 162367489,162367489 ] & {$[68007294,68007294\rfloor$} \\
\hline FB & {$[17739,17739]$} & 〔 $7395030,7395030 〕$ & 〔 13157079,13157079$]$ & 〔 401449260,401449260 ] & {$[68097646,68097646]$} \\
\hline GL & {$[614,614]$} & {$[113524,113524]$} & {$[479299,479299]$} & $\{8516802,8516802\rceil$ & $\lceil 1180712,1180712 〕$ \\
\hline MLI & $\lceil 6773,6773\rceil$ & $\lceil 4226604,4226604]$ & {$[3876625,3876625]$} & 〔 103890522,103890522 ] & {$[15315113,15315113]$} \\
\hline CYL & {$[249,249]$} & {$[155506,155506$ ] } & {$[304794,304794]$} & 〔8495689, 8495689 & {$[490649,490649]$} \\
\hline SL & {$[686,686]$} & {$[17053,17053]$} & {$[760784,760784\rfloor$} & 〔8693829, 8693829〕 & {$[1790980,1790980 〕$} \\
\hline FL & {$[1763,1763]$} & 〔 $8726315,8726315 〕$ & 〔 1620986,1620986$]$ & 〔 36498273,36498273 ] & 〔 13424564,13424564$]$ \\
\hline HL & {$[485,485]$} & 〔302639, 302639$]$ & $\{625861,625861\rceil$ & 〔22618716, $22618716 〕$ & {$[5187520,5187520]$} \\
\hline AL & {$[1316,1316]$} & {$[113180,113180]$} & 〔 1215181,1215181$]$ & 〔 $4679402,4679402 〕$ & {$[659860,659860]$} \\
\hline FI & {$[188,188]$} & $\lceil 4851,4851 〕$ & {$[364400,364400]$} & $\lceil 2474901,2474901 〕$ & {$[368779,368779]$} \\
\hline PL & $\lceil 1152,1152]$ & $〔 1365586,1365586 〕$ & {$[1712333,1712333]$} & 〔 $11474736,11474736 〕$ & $\lceil 1661718,1661718 〕$ \\
\hline TGL & {$[926,926]$} & 〔 178686,178686 ] & {$[1796514,1796514]$} & 〔25191738, $25191738 〕$ & 〔 $8825842,8825842 〕$ \\
\hline NYL & {$[640,640]$} & {$[33067,33067\}$} & {$[1047296,1047296]$} & 〔 11006193,11006193$]$ & 〔 $1787727,1787727 〕$ \\
\hline CL & {$[938,938 〕$} & 〔 168366,168366 ) & 〔 2314288,2314288$]$ & 〔 $7346983,7346983 〕$ & $\begin{array}{r}(171220+7311546 \alpha \\
119271028-111788262 \alpha)\end{array}$ \\
\hline ML & {$[1376,1376]$} & {$[50964,50964]$} & {$[921294,921294]$} & 〔6892806, 6892806〕 & {$[736459,736459]$} \\
\hline $\mathrm{CO}$ & $\lceil 255,255]$ & $\lceil 20748,20748 〕$ & {$[925367,925367]$} & 〔 $3037692,3037692 〕$ & {$[171220,171220]$} \\
\hline maximum & 30,889 & $20,508,928$ & $16,134,194$ & $471,820,605$ & $119,271,028$ \\
\hline minimum & 188 & 4,851 & 304,794 & $2,474,901$ & 171,220 \\
\hline median & 1,316 & 302,639 & $1,620,986$ & $22,618,716$ & $7,482,766$ \\
\hline
\end{tabular}


Table A.2: Life insurance company upper and lower limits of efficiency in input and output in 2012

\begin{tabular}{|c|c|c|c|c|c|c|c|c|c|c|c|c|c|c|c|c|c|c|c|c|c|c|c|}
\hline \multirow[t]{2}{*}{$\overline{\mathrm{DMU}}$} & \multicolumn{2}{|l|}{$\alpha=0$} & \multicolumn{2}{|c|}{$\alpha=0.1$} & \multicolumn{2}{|c|}{$\alpha=0.2$} & \multicolumn{2}{|l|}{$\alpha=0.3$} & \multicolumn{2}{|c|}{$\alpha=0.4$} & \multicolumn{2}{|l|}{$\alpha=0.5$} & \multicolumn{2}{|l|}{$\alpha=0.6$} & \multicolumn{2}{|c|}{$\alpha=0.7$} & \multicolumn{2}{|l|}{$\alpha=0.8$} & \multicolumn{2}{|l|}{$\alpha=0.9$} & \multicolumn{2}{|l|}{$\alpha=1$} & \multirow{2}{*}{ score } \\
\hline & $\mathrm{L}$ & $\mathrm{U}$ & $\mathrm{L}$ & $\mathrm{U}$ & $\mathrm{L}$ & U & $\mathrm{L}$ & $\mathrm{U}$ & $\mathrm{L}$ & $\mathrm{U}$ & $\mathrm{L}$ & $\mathrm{U}$ & $\mathrm{L}$ & $\mathrm{U}$ & $\mathrm{L}$ & $\mathrm{U}$ & $\mathrm{L}$ & $\mathrm{U}$ & $\mathrm{L}$ & U & $\mathrm{L}$ & $\mathrm{U}$ & \\
\hline TB & 1.000 & 1.000 & 1.000 & 1.000 & 1.000 & 1.000 & 1.000 & 1.000 & 1.000 & 1.000 & 1.000 & 1.000 & 1.000 & 1.000 & 1.000 & 1.000 & 1.000 & 1.000 & 1.000 & 1.000 & 1.000 & 1.000 & 00 \\
\hline TL & 705 & 0.712 & 0.705 & 0.712 & 705 & 712 & 0.706 & 712 & 706 & 0.712 & 0.706 & 712 & 0.707 & 0.712 & 707 & 0.712 & 0.709 & 0.712 & .712 & 0.712 & 0.712 & 0.712 & .607 \\
\hline PCL & 1.000 & 1.000 & 1.000 & 1.000 & 1.000 & 1.000 & 1.000 & 1.000 & 000 & 1.000 & 1.000 & 1.000 & 1.000 & 1.000 & 1.000 & 1.000 & 1.000 & 1.000 & 1.000 & 1.000 & 1.000 & 1.000 & 1.000 \\
\hline CA & 1.000 & 1.000 & 1.000 & 1.000 & 000 & 1.000 & 1.000 & 1.000 & .000 & 1.000 & 1.000 & 1.000 & 1.000 & 1.000 & 1.000 & 1.000 & 1.000 & 1.000 & 1.000 & 1.000 & 1.000 & 1.000 & 1.000 \\
\hline CL & 1.000 & 1.000 & 1.000 & 1.000 & 000 & 1.000 & .000 & 1.000 & 000 & 1.000 & 1.000 & 1.000 & 1.000 & 1.000 & 1.000 & 1.000 & 1.000 & 1.000 & 1.000 & 1.000 & 1.000 & 1.000 & 1.000 \\
\hline NL & 0.945 & 1.000 & 0.961 & 1.000 & 0.978 & 1.000 & 0.996 & 1.000 & .000 & 1.000 & 1.000 & 1.000 & 1.000 & 1.000 & 1.000 & 1.000 & 1.000 & 1.000 & 1.000 & 1.000 & 1.000 & 1.000 & 0.985 \\
\hline KL & 1.000 & 1.000 & 1.000 & 1.000 & 1.000 & 1.000 & 1.000 & 1.000 & 000 & 1.000 & 1.000 & 1.000 & 1.000 & 1.000 & 1.000 & 1.000 & 1.000 & 1.000 & 1.000 & 1.000 & 1.000 & 1.000 & 1.000 \\
\hline SK & 0.638 & 1.000 & 0.641 & 1.000 & 0.646 & 1.000 & 0.651 & 1.000 & 659 & 1.000 & 0.703 & 1.000 & 0.808 & 1.000 & 0.992 & 1.000 & 1.000 & 1.000 & 1.000 & 1.000 & 1.000 & 1.000 & 0.783 \\
\hline $\mathrm{B}$ & 1.000 & 1.000 & 1.000 & 1.000 & 1.000 & 1.000 & 1.000 & 1.000 & .000 & 1.000 & 1.000 & 1.000 & 1.000 & 1.000 & 1.000 & 1.000 & 1.000 & 1.000 & 1.000 & 1.000 & 1.000 & 1.000 & 1.000 \\
\hline GL & 0.889 & 0.889 & 0.889 & 0.889 & 0.889 & 0.889 & 0.889 & 0.889 & 889 & 0.889 & 0.889 & 0.889 & 0.889 & 0.889 & 0.889 & 0.889 & 0.889 & 0.889 & 0.889 & 0.889 & 0.889 & 0.889 & 0.849 \\
\hline MLI & 0.761 & 0.761 & 0.761 & 0.761 & 0.761 & 0.761 & 0.761 & 0.761 & .761 & 0.761 & 0.761 & 0.761 & 0.761 & 0.761 & 0.761 & 0.761 & 0.761 & 0.761 & 0.761 & 0.761 & 0.761 & 0.761 & 0.677 \\
\hline CYL & 1.000 & 1.000 & 1.000 & 1.000 & 1.000 & 1.000 & 1.000 & 1.000 & 1.000 & 1.000 & 1.000 & 1.000 & 1.000 & 1.000 & 1.000 & 1.000 & 1.000 & 1.000 & 1.000 & 1.000 & 1.000 & 1.000 & 1.000 \\
\hline SL & 1.000 & 1.000 & 1.000 & 1.000 & 1.000 & 1.000 & 1.000 & 1.000 & 000 & 1.000 & 1.000 & 1.000 & 1.000 & 1.000 & 1.000 & 1.000 & 1.000 & 1.000 & 1.000 & 1.000 & 1.000 & 1.000 & 000 \\
\hline L & 0.698 & 1.000 & 0.703 & 1.000 & 0.708 & 1.000 & 0.715 & 1.000 & 0.726 & 1.000 & 0.742 & 1.000 & 0.764 & 1.000 & 0.799 & 1.000 & 0.862 & 1.000 & 1.000 & 1.000 & 1.000 & 1.000 & 0.781 \\
\hline HL & 1.000 & 1.000 & 1.000 & 1.000 & 1.000 & 1.000 & 1.000 & 1.000 & .000 & 1.000 & 1.000 & 1.000 & 1.000 & 1.000 & 1.000 & 1.000 & 1.000 & 1.000 & 1.000 & 1.000 & 1.000 & 1.000 & 1.000 \\
\hline AL & 0.325 & 0.325 & 0.325 & 0.325 & 0.325 & 0.325 & 0.325 & 0.325 & 0.325 & 0.325 & 0.325 & 0.325 & 0.325 & 0.325 & 0.325 & 0.325 & 0.325 & 0.325 & 0.325 & 0.325 & 0.325 & 0.325 & 0.088 \\
\hline I & 1.000 & 1.000 & 1.000 & 1.000 & 1.000 & 1.000 & 1.000 & 1.000 & 000 & 1.000 & 1.000 & 1.000 & 1.000 & 1.000 & 1.000 & 1.000 & 1.000 & 1.000 & 1.000 & 1.000 & 1.000 & 1.000 & 1.000 \\
\hline PL & 0.260 & 0.263 & 0.260 & 0.263 & 0.261 & 0.263 & 0.261 & 0.263 & 0.261 & 0.263 & 0.261 & 0.263 & 0.261 & 0.263 & 0.262 & 0.263 & 0.263 & 0.263 & 0.263 & 0.263 & 0.263 & 0.263 & 0.004 \\
\hline TGL & 1.000 & 1.000 & 1.000 & 1.000 & 1.000 & 1.000 & 1.000 & 1.000 & 1.000 & 1.000 & 1.000 & 1.000 & 1.000 & 1.000 & 1.000 & 1.000 & 1.000 & 1.000 & 1.000 & 1.000 & 1.000 & 1.000 & 1.000 \\
\hline NYL & 0.984 & 0.984 & 0.984 & 0.984 & 0.984 & 0.984 & 0.984 & 0.984 & 0.984 & 0.984 & 0.984 & 0.984 & 0.984 & 0.984 & 0.984 & 0.984 & 0.984 & 0.984 & 0.984 & 0.984 & 0.984 & 0.984 & 0.978 \\
\hline CL & 0.309 & 1.000 & 0.309 & 1.000 & 0.309 & 1.000 & 0.374 & 1.000 & 0.443 & 1.000 & 0.513 & 1.000 & 0.583 & 1.000 & 0.653 & 1.000 & 0.723 & 1.000 & 0.793 & 1.000 & 0.864 & 0.864 & 0.610 \\
\hline ML & 0.623 & 0.623 & 0.623 & 0.623 & 0.623 & 0.623 & 0.623 & 0.623 & 0.623 & 0.623 & 0.623 & 0.623 & 0.623 & 0.623 & 0.623 & 0.623 & 0.623 & 0.623 & 0.623 & 0.623 & 0.623 & 0.623 & 0.490 \\
\hline 0 & 0.765 & 0.765 & 0.765 & 0.765 & 0.765 & 0.765 & 0.765 & 0.765 & 0.765 & 0.765 & 0.765 & 0.765 & 0.765 & 0.765 & 0.765 & 0.765 & 0.765 & 0.765 & 0.765 & 0.765 & 0.765 & 0.765 & 0.682 \\
\hline
\end{tabular}

